\title{
Fantasias de Lucia e Alice: práticas lúdicas com literatura na difusão científica sobre sustentabilidade
}

\author{
Thaís Saboya Teixeira ${ }^{1}$ \\ Luís Paulo de Carvalho Piassi ${ }^{2}$
}

Resumo: Em meio a diversos problemas ambientais e sociais advindos de um crescimento desenfreado das civilizações, a sustentabilidade surge como um caminho para tentar solucionar tais questões e permitir um convívio saudável com o ambiente no qual estamos inseridos. Entende-se então que seja um tema relevante que deve ser tratado com todas as idades. Desta maneira, o presente trabalho tem como intuito apresentar novas formas de abordar a sustentabilidade com alunos do ensino fundamental II, através de atividades de difusão científica que se utilizam de práticas lúdicas e da literatura como instrumentos principais. Tais atividades são desenvolvidas dentro do projeto de extensão universitária ALICE, da USP em parceria com a UNIFESP e o IFSP.

Palavras-chave: difusão científica, literatura juvenil, sustentabilidade, práticas lúdicas, agenda 2030.

Fantasies of LUCIA and ALICE:

Playful practices with literature in the science outreach on sustainability

Abstract: Among the many environmental and social problems arising from unbridled growth of civilizations, sustainability emerges as a way to try to resolve these issues and allow a healthy coexistence with the environment in which we operate. It is understood that it's an important issue that should be dealt with all ages. So, this work has the intention to present new ways to approach sustainability with elementary school students through scientific dissemination activities that use playful practices and literature as main instruments. These activities are developed within the university outreach project ALICE, that is a partnership among USP, UNIFESP and IFSP.

Keywords: science dissemination, juvenile literature, sustainability, playful practices, 2030 agenda

${ }^{1}$ Graduanda no curso de Bacharelado em Lazer e Turismo na Universidade de São Paulo.

${ }^{2}$ Professor Doutor na Escola de Artes, Ciências e Humanidades da USP. Bacharel e Licenciado em Física pela USP (1990), Mestre em Ensino de Ciências pela USP (1995), Doutor em Educação pela Faculdade de Educação da USP, Livre-Docente em Artes, Cultura e Lazer pela Escola de Artes, Ciências e Humanidades da USP (2012).

\begin{tabular}{l|l|l|l|l|} 
Textura & Canoas & v. 19 n.39 & p. 35-57 & jan./abr. 2017 \\
\hline
\end{tabular}




\section{INTRODUÇ̃̃O}

Quando se trabalha com a difusão da ciência e pretende-se levá-la para novos públicos, alguns desafios surgem pelo caminho. Entre eles estão o que levar e como levar. O primeiro porque precisa ser um tema relevante e como muitos são importantes, não há tempo para desenvolver todos, precisando assim fazer a escolha de um que seja considerado mais pertinente. O segundo desafio surge porque a difusão científica precisa, essencialmente, ser atrativa aos olhos do público. Isso porque ela não traz consigo nenhuma obrigatoriedade. Não é uma aula onde as presenças estão sendo contadas e os indivíduos precisam estar ali, mas ao contrário, é um tipo de intervenção onde os participantes vão por própria vontade, o que exige que seja algo envolvente para o público, onde haja uma identificação.Dentre todos os temas possíveis de serem escolhidos, a sustentabilidade é definida como um dos principais. Não apenas por ser um assunto muito debatido em todo o mundo, mas também porque afeta diretamente a todas as pessoas e as ações de cada uma delas afetam diretamente a sustentabilidade.

O ALICE (Arte e Lúdico na Investigação da Ciência nos Espaços Educativos) é a vertente voltada para pré-adolescentes do projeto de extensão universitária Banca da Ciência que aborda temas socio científicos e culturais através da difusão científica, realizado pela USP em conjunto com a UNIFESP e IFSP. Ele subdivide-se em seis equipes, cada uma com sua abordagem específica. O presente trabalho é desenvolvido inteiramente dentro da equipe LUCIA (Leituras Universais e Criatividade na Investigação da Arte-Ciência), onde a matéria-prima principal são as obras literárias de fantasia.A literatura é vista como um instrumento para elaborar tais atividades e difundir não apenas conteúdos científicos, mas também a própria narrativa em questão.Dentro dela destaca-se a ficção científica, um gênero que oferece diversas obras para tratar de sustentabilidade, entre outras temáticas. É ainda uma maneira de falar sobre assuntos sociais e tecnológicos com enfoque em refletir sobre o presente e pensar no futuro (Autor, 2007).Ainda em auxílio para a elaboração de uma atividade de difusão científica, conta-se com abordagens lúdicas, pois são capazes de promover maior liberdade aos indivíduos e os tiram do modelo formal pelo qual estão acostumados a discutir ciência. O lúdico proporciona momentos de descontração, onde diminui-se a inibição dos participantes e permite maior troca de conhecimentos. 


\section{A DIFUSÃo CIENTÍFICA E O LÚDICO}

Segundo Almeida e Rincón, para um bom desempenho nas disciplinas escolares é necessário que haja o interesse pelo assunto e a grande dificuldade está em como desperta-lo nos alunos para que assim possa haver o entendimento do mesmo. No caso da física, por exemplo, a grande crítica é que há muito pouco uso da linguagem comum durante as aulas, o que inibe as participações nas atividades (ALMEIDA \& RICON, 1993).Isso se aplica também a diversas outras práticas educativas, que pretendem levar o conhecimento sem antes despertar o interesse pelo assunto. E o grande desafio está em como transformar um tema que antes era indiferente ou desinteressante, em algo verdadeiramente atrativo. Atividades lúdicas tem se mostrado positivas nesse aspecto, sendo educativas a partir do momento em que são criadas intencionalmente para estimular algum tipo de aprendizado conforme defende Tizuko Kishimoto (1999).Além disso configuram-se muitas vezes como práticas de lazer, que como coloca Renato Requixa (1977), são práticas capazes de proporcionar desenvolvimento pessoal e social. Tais ideias são consistentes com a concepção da educação não como forma de reproduzir informações, mas como estímulo ao pensamento crítico de cada estudante.

Para Sarita Albagli (1996, p. 397) quando tratamos de divulgação científica supõe-se "a tradução de uma linguagem especializada para uma leiga, visando a atingir um público mais amplo".

Além disso, pode se orientar para alguns objetivos, como educacionais, cívicos e de mobilização popular. Aqui trataremos da educacional, que pretende esclarecer conteúdos já estudados bem como abordar aspectos culturais, despertando a curiosidade acerca dos temas científicos (ALBAGLI, 1996).A divulgação científica - ou difusão científica, como irá ser chamada aqui - educacional não precisa necessariamente acontecer na escola, podendo se apropriar de espaços públicos e privados diversificados, como bibliotecas, museus, entre outros. No entanto, quando ela acontece no ambiente escolar é preciso desenvolver uma relação topofílica do participante com o lugar. De acordo com Aline Tschoke e colaboradores, "a escola passou a ser na sociedade moderna um dos espaços privilegiados para que as crianças possam experienciar a dimensão lúdica“" (TSCHOKE et al, 2008, p. 511). No entanto segundo a mesma autora, esses espaços só se tornarão lúdicos a partir do momento em que forem apropriados pelos alunos, através da vivência e da experiência. Para ela, "essa apropriação que transforma o espaço em lugar acontece quando se estabelece um contrato entre o sujeito e o ambiente, através de diferentes formas de comunicação" (TSCHOKE et al, 2008, p. 
513).Dessa maneira a partir do momento que se ligam práticas lúdicas à difusão científica, cria-se não apenas uma afinidade do participante em relação ao lugar, mas também a curiosidade e o prazer a respeito do assunto proposto. Isto porque o saber está sendo tratado de maneira muito mais simples e atrativa do que se está acostumado.

\section{ABORDAGENS DA LITERATURA SOBRE SUSTENTABILIDADE}

Sustentabilidade é a palavra-chave para as questões ambientais discutidas nos últimos anos e também para os próximos. Exemplo disso é a Agenda $2030^{3}$ firmada em 2015. De 25 a 27 de setembro de 2015, mais de 150 líderes mundiais se reuniram na sede da ONU em Nova York para oficializar os 17 objetivos para o desenvolvimento sustentável, que devem servir como plano de ação para os próximos anos.As metas pretendem não deixar ninguém para trás, incluindo objetivos como água potável e saneamento, energia limpa e acessível, trabalho decente e crescimento econômico, ação contra a mudança global e do clima, vida na água, vida terrestre, entre outros. Ainda é importante lembrar que essas propostas foram feitas em base dos resultados dos Objetivos de Desenvolvimento do Milênio (acordo feito anteriormente que estabelecia oito Jeitos de Mudar o Mundo), com a intenção de concluir os pontos que ficaram inacabados.

Quando se fala de desenvolvimento, o economista indiano Amartya Sen (2000) defende que para isso acontecer é preciso lembrar da importância das liberdades. Um grande número de pessoas sofre de fome coletiva, possui pouco ou nenhum acesso a serviços de saúde, saneamento básico e água tratada, o que as priva da liberdade primordial de sobrevivência. Essas são questões básicas que precisam ser solucionadas para que seja possível obter avanços em outras áreas. Ignacy Sachs (1993) já previa como meta fazer com que as pessoas subissem para além da linha da pobreza para que assim, ao remover os obstáculos que anteriormente os impediam de ter uma visão a longo prazo, fossem capazes de agir de maneira não-agressiva ao ambiente que os cerca.Dessa forma, para que seja possível o desenvolvimento sustentável é necessário que se erradiquem as desigualdades, afim de que todos possam ter uma vida digna, de qualidade e que sejam capazes,assim, de suprir suas próprias necessidades entrando em equilíbrio com o meio ambiente. É nessa linha que se observa a Agenda 2030 se estabelecer, buscando acabar com a miséria e aumentar a qualidade de vida ao passo em que se preservam os

\footnotetext{
${ }^{3}$ Vide https://nacoesunidas.org/pos2015/agenda2030/
} 
recursos naturais, com o comprometimento coletivo de todos os países participantes.

Mas a preocupação com a sustentabilidade não se restringe apenas a grandes instituições e pesquisadores, sendo também facilmente observada na literatura, onde não faltam obras abordando essas temáticas. Há décadas encontram-se narrativas de ficção que retratam de alguma maneira as questões ambientais, prefigurando possíveis futuros, e ainda hoje este é um assunto que se faz presente em suas páginas. A ficção científica é um gênero que apresenta uma abordagem peculiar de saberes socioculturais. Este tipo de história é capaz de criar relações entre as preocupações da sociedade com o futuro, levando em conta o presente momento (Autor, 2015). Tendo em vista que as inquietações a respeito da natureza sejam um assunto que está sempre em pauta e confere-se como uma ansiedade coletiva em diversas partes do mundo, é natural que se encontrem narrativas de ficção científica falando sobre esse tema, o que é importante por alguns motivos.

Primeiramente por ser um assunto pertinente a todos, é extremamente relevante que se encontre em pauta, seja no meio acadêmico, corporativo e cultural, nesse caso, na literatura. Além disso, a ficção científica envolve o leitor em um novo mundo, onde ele pode experimentar as sensações daquilo que está sendo retratado (Autor, 2015). Dessa forma é relevante que sejam mencionadas algumas obras que cumprem esse papel.

Começando por Isaac Asimov (1991), autor conhecido por escrever livros e contos dentro desse gênero, pode-se citar o conto "O Fura-Greves" ("Strikebreaker"), publicado originalmente em 1957,que trata diretamente de sustentabilidade ao retratar um planetoide onde absolutamente tudo precisa ser reutilizado. É possível observar claramente um desafio que ainda é atual - o de reciclar e reutilizar os produtos e objetos- sendo retratado em outro cenário.Essas abordagens não se limitam apenas aos romances de ficção científica, mas várias obras de fantasia acabam por trabalhar aspectos da sustentabilidade de uma maneira ou de outra, como é o caso de "Jogos Vorazes" ("The Hunger Games"), de Suzanne Collins (2010), publicado originalmente em 2008, leva o leitor a um universo onde todos estão inseridos em um regime não democrático, no qual grande parte das pessoas vive em condições de extrema pobreza, alimentando-se através da caça e obtendo produtos por meio de trocas, por exemplo, se alguém cultiva ervas medicinais pode trocar seus produtos com alguém que seja capaz de caçar, por um pedaço de pão, assim por diante.Datando de épocas diferentes, é possível observar que 
a preocupação com esses aspectos tem vigorado por anos. Cada uma dessas narrativas se propõe a transferir o leitor para um universo diferente, onde poderá vivenciar novas sensações, ora em ambientes totalmente sustentáveis onde nada é desperdiçado, ora em lugares onde os recursos já se tornaram extremamente escassos. Essas experiências permitem que o indivíduo reflita com um novo ponto de vista acerca da sustentabilidade e a partir daí seja capaz de tomar atitudes para -tentar- solucionar os problemas com que se depara no cotidiano em relação ao meio em que vive. Estes exemplos são apenas uma pequena parte do que há na literatura a respeito de sustentabilidade e consistem em materiais empregados por nossa equipe para a formulação de intervenções de difusão científica.

\section{O PROJETO ALICE E A EQUIPE LUCIA}

$\mathrm{O}$ presente trabalho tem como origem a iniciativa A.L.I.C.E. (Arte e Lúdico na Investigação da Ciência nos Espaços Educativos), um projeto de extensão universitária da Universidade de São Paulo em parceria com a Universidade Federal de São Paulo e o Instituto Federal de São Paulo, que trata de temas sociocientíficos e culturais a partir de práticas lúdicas. O ALICE subdivide-se em seis grupos, cada com sua proposta específica. São eles: DIAN (Debates e Investigações sobre os Animais e a Natureza), EMMA (Estudos sobre as Mulheres e Minorias na Arte-Ciência), LIRA (Laboratório de Investigação em Robótica e Astronáutica), LUCIA (Leituras Universais e Criatividade na Investigação da Arte-Ciência), MARIA (Manifestações da Alegria e da Recreação na Investigação da Arte-Ciência) e RITA (Ritmos na Investigação da Tecnologia e da Arte-Ciência).

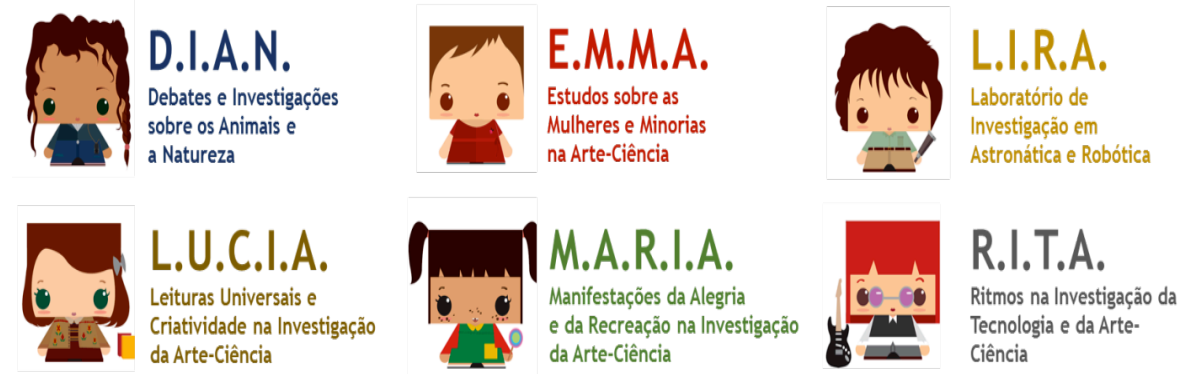

Figura 1. Equipes do projeto e seus logogramas. llustração: Alina H. Paradiso (bolsista do projeto). 
Cada grupo conta com estudantes de graduação de diversos cursos ${ }^{4}$ e pósgraduação que se reúnem semanalmente para discutir temas pertinentes e elaborar atividades de difusão científica que são aplicadas em escolas públicas de São Paulo. Também participam estudantes de ensino médio vinculados a programas de pré-iniciação científica. $\mathrm{O}$ desenvolvimento do trabalho foi feito integralmente dentro da equipe LUCIA, que tem como princípio criar atividades a partir de obras literárias de fantasia dos mais diversos estilos, em especial ficção científica. A partir do tema a ser tratado com a turma em questão, encontra-se uma obra que trate de algum assunto específico dentro daquela temática, definindo os objetivos e a partir daí desenvolve-se uma proposta para ser realizada. O LUCIA é liderado por uma integrante de pósgraduação, Mestre em Educação, sete integrantes de graduação, dos cursos de Licenciatura em Ciências da Natureza e Bacharelado em Lazer e Turismo, Têxtil e Moda, Marketing e Gestão Ambiental, além de um estudante de ensino médio vinculado ao programa de pré-iniciação científica. As intervenções acontecem com diferentes idades, incluindo jovens do ensino fundamental II em uma escola municipal da rede pública localizada na zona leste de São Paulo (Escola A) e de ensino fundamental II e ensino médio com a uma escola estadual da rede pública, também na zona leste da cidade (Escola B).

As equipes se revezam a partir de um cronograma semestral e a cada semana acontecem intervenções nestas escolas, que são previamente planejadas e pretendem abordar saberes científicos a partir de práticas lúdicas. Essas abordagens acontecem a partir de diferentes artefatos e práticas culturais, como músicas, filmes, livros, séries e costumam estimular que os alunos produzam algum produto, que pode ser por meio de pinturas, desenhos, colagens, assim por diante. As atividades realizadas nessas escolas possuem as temáticas previamente estipuladas. Aqui trataremos especificamente do caso dos alunos da Escola A.

Esta escola participa de um projeto da prefeitura que propõe alterações no Sistema Municipal de Ensino intitulado "Mais Educação São Paulo", Ele tem como objetivo promover melhorias no ensino e aprendizado da rede pública e permaneceu em consulta pública durante 30 dias para que recebesse contribuições de pais, professores e alunos. Consolida-se então com algumas

\footnotetext{
${ }^{4}$ Licenciatura em Ciências da Natureza e Bacharelados em Lazer e Turismo, Gestão Ambiental, Gestão de Políticas Públicas, Marketing, Obstetrícia, Sistemas de Informação e Têxtil e Moda.

${ }^{5}$ Vide página do programa em http://maiseducacaosaopaulo.prefeitura.sp.gov.br.
} 
medidas importantes, como a maior carga horária de matérias como português e matemática, ampliar a oferta de vagas e a valorização do educador. Grande parte das atividades desse projeto são voltadas a esportes e músicas, raramente havendo propostas ligadas à ciência. O A.L.I.C.E. surge então como uma proposta para a abordagem dessa temática.

Dentro da Escola A o projeto foi instituído com a parceria de três professores, que se comprometem a dar todo o suporte necessário para as intervenções, bem como promover outras atividades com os alunos por conta própria. O contato entre alunos, professores e LUCIA permite que haja sintonia entre as propostas, de maneira a compreender as necessidades dos alunos e oferecer intervenções consistentes e complementares entre si. O encontro com os alunos se dá em "horários de contraturno (fora das aulas) ou durante aulas específicas de projetos interdisciplinares" (CRUZ, 2016, p. 8).Para o ano de 2015, foram criados três projetos "Mais Educação São Paulo" nessa escola, com os temas "Robótica", "Espaço" e "Meio Ambiente", cada um com um professor como responsável. No início do ano, os alunos escolheram um dos projetos para participar. Sua participação é voluntária, podendo ir com a frequência que desejarem e até mesmo sair do projeto caso queiram. Entra como função dos professores e dos integrantes do projeto elaborarem atividades atrativas que estimulem a participação de todos. A coleta de dados se dá por meio de fotos, filmagens, observações e tomada de notas por parte dos monitores, que se dividem para que seja possível realizar todas essas tarefas. A equipe LUCIA atuou, durante o primeiro semestre de 2016, com intervenções nos três projetos "Mais Educação São Paulo". A seguir é possível observar uma breve descrição analítica de todas as atividades da equipe realizadas nesse período:

\begin{tabular}{ll}
\hline Projeto & \multicolumn{1}{c}{ Descrição da intervenção } \\
\hline Robótica & \multicolumn{1}{c}{ A partir da obra "Sonhos de Robô" de Isaac } \\
$(15 / 03 / 2016)$ & $\begin{array}{l}\text { Asimov (1991), realiza-se uma proposta onde é } \\
\text { contada a história para os alunos sem revelar o final, }\end{array}$ \\
& a fim de que possam propor qual seria seu desfecho e \\
& com o objetivo principal de questionar o uso dos \\
& robôs pelos humanos. Os robôs sonham? São apenas \\
& máquinas cumprindo seu papel ou poderiam ter \\
& sentimentos? Durante a atividade realizada com seis \\
& alunos, questiona-se sobre robôs sonharem e eles não
\end{tabular}




\begin{tabular}{l} 
descartam a possibilidade. Em seguida, são sugeridos \\
alguns tipos de sonho, como "ter corpo" (sujeito 4) ou \\
"ser livres" como afirma o sujeito 2 , que diz ter visto \\
filmes onde robôs são tratados como escravos. Neste \\
momento a história ainda não havia sido contada aos \\
alunos, configurando-se apenas em uma conversa \\
inicial.o fato do sujeito 2 já ter visto abordagens \\
onde os robôs são tratados como escravos estabelece \\
um contato prévio com o assunto a ser tratado no \\
conto e pressupõe que possa facilitar sua reflexão \\
sobre o assunto.No decorrer da discussão inicial, após \\
serem apontados aspectos considerados negativos em \\
"ser um robô", a monitora 1 sugere que um aspecto \\
positivo seja o fato dos robôs não sentirem dor, o que \\
é rebatido pelo aluno:[Sujeito 2]: Mas sentir dor faz \\
parte de quem nós somos.Esta visão mostra que o \\
fato de não sentir dor não é visto necessariamente \\
como uma vantagem pelo aluno, uma vez que ela é \\
encarada como algo natural. Este posicionamento \\
inesperado e contrário a sugestão da monitora \\
mostra como as opiniões se contrapõe no meio da \\
atividade, o que estimula a discussão e o pensamento \\
crítico de todos os participantes. \\
"É proposta uma dinâmica a partir do conto \\
"O Fura-Greves", de Isaac Asimov (1991) onde a \\
história é contada para os alunos, mas sem revelar o \\
final, afim de despertar a curiosidade a respeito do \\
desfecho. A narrativa se passa em um planetoide \\
onde absolutamente tudo precisa ser reutilizado e a \\
sociedade divide-se em um sistema de castas. Os \\
coletores de fezes pertencem a um grupo excluído da \\
sociedade, que apesar de possuírem boa condição \\
financeira, podem relacionar-se apenas entre si. Em \\
determinado momento, cansam-se dessa divisão e \\
entram em greve, causando prejuízo a todos, já que \\
sua tarefa era de extrema importância para todos. É \\
\hline Meio
\end{tabular}


feita uma discussão a respeito dos principais pontos da história e sugerido que os alunos desenhem, em grupos, o ponto que mais se destacou na história. Para isso são disponibilizados diversos materiais, como tinta, fitas adesivas, lápis de cor, entre outros. Surgem desenhos sobre a fábrica em greve, a vida dos coletores, bem como diferenças encontradas na sociedade atual entre os estilos de vida de quem possui mais ou menos dinheiro. Posteriormente seguem para a última etapa, onde devem imaginar que criarão um canal sobre sustentabilidade $e$ elaborar um roteiro para um possível vídeo, apontando os temas a serem tratados. A proposta gera empolgação e timidez entre os participantes. As dificuldades que surgem são especialmente com o tempo e a forma de elaborar o roteiro, pois possuem poucos minutos e não estão acostumados a trabalhar com o sistema de tópicos (sugerido pelos monitores). Apesar das dificuldades um dos grupos se destaca e elabora toda a introdução de seu vídeo, em primeira pessoa.

Robótica

(12/04/2016)

Nesta atividade a proposta é que criem uma história em quadrinhos que precisa necessariamente ter um robô, uma figura que crie problemas e outra que salve o dia (o robô pode se encaixar em uma dessas categorias caso achem adequado). A dinâmica proposta é a seguinte: cada um diz o que acontece na história em um quadrinho e depois o colega ao lado continua de onde parou. Posteriormente cada um ilustra o quadro que inventou para que ao final juntem todos os desenhos e vire uma grande história em quadrinhos. Observa-se o papel em que o robô é colocado quando o sujeito 7 insere-o na história caracterizando-o como "maligno". O sujeito 8 prossegue dizendo que o robô declara guerra e 0 sujeito 10 diz que ele matou os heróis. Essas três 


\begin{tabular}{l} 
participações colocam-no como vilão da história. \\
Quem muda essa visão é o sujeito 11, que insere mais \\
um robô, dessa vez disfarçado de cientista, que \\
consegue derrotar o robô maligno. Apenas nesse \\
momento o robô é visto como uma figura boa capaz \\
de solucionar problemas. Ainda assim aparece \\
disfarçado de cientista, o que leva a entender que o \\
cientista é a figura a ser vista como heroica. Ainda se \\
nota a ausência de personagens negros e mulheres na \\
história criada, o que é discutido com a sala. \\
\hline É elaborado um jogo de tabuleiro gigante \\
utilizando como base o livro Jogos Vorazes, de \\
Ambio \\
Suzanne Collins (2010), que é delimitado no chão com \\
fita adesiva e em cada casa é colado um papel que \\
indica o que o participante deve fazer. A temática do \\
jogo gira toda em torno da história do livro, que se \\
passa em um regime não democrático, onde a \\
sociedade é dividida em distritos. Cada distrito possui \\
suas características individuais, mas as desigualdades \\
entre eles e a Capital são gritantes. A relação com a \\
natureza é muito próxima, já que várias famílias \\
vivem da caça ou dos frutos que conseguem. Para \\
jogar a sala deve dividir-se em grupos e escolher um \\
dos integrantes para ser o peão, ou seja, a pessoa que \\
jogará o dado e andará pelo tabuleiro. O diferencial é \\
que em determinadas casas o participante encontrará \\
um trecho do livro para ser lido. Depois ele e seu \\
grupo deverão responder uma pergunta referente \\
àquilo e os outros grupos avaliarão se a resposta foi \\
satisfatória ou não, devendo justificar o porquê \\
quando não concordarem. A dinâmica do jogo flui \\
bem, contudo, possuem maior facilidade em \\
responder determinadas questões e mostram certa \\
dificuldade em outras. No livro, o distrito onde os \\
personagens vivem é separado da floresta por uma \\
cerca. A pergunta é o porquê da cerca fazer essa
\end{tabular}




\begin{tabular}{l} 
separação e se há alguma semelhança entre essa \\
relação da natureza com o urbano em nossa \\
sociedade. É respondido com facilidade que a cerca \\
está ali pois existem animais selvagens na floresta e \\
que vemos sim relações em nossa sociedade, já que é \\
comum ver os espaços urbanos bem separados de \\
áreas naturais. Outras perguntas geram maior \\
dificuldade para serem respondidas. Em uma das \\
casas o trecho faz referência a alguns pássaros que \\
foram usados pela Capital e posteriormente \\
abandonados. A pergunta é sobre como os animais \\
são usados pelos seres humanos e pede-se que sejam \\
citados alguns exemplos do uso dos animais pelos \\
humanos. Esta questão gera bastante dificuldade e \\
depois de algum tempo de conversa entre si \\
conseguem pensar no caso dos cavalos que puxam \\
carroças. Nesta atividade são tratadas relações entre \\
humanos e animais, sociedade e natureza, \\
entendendo que são discussões importantes para \\
trazer em pauta. \\
Ét utilizado o livro "O Guia do Mochileiro das \\
Galáxias" de Douglas Adams (2009), onde a toalha é \\
tida como o objeto mais importante para levar pelo \\
Universo, pois pode ser usada para as mais inusitadas \\
funções. Nesta atividade conta-se para os alunos um \\
pouco da história, bem como a importância da toalha \\
e sugere-se que cada um customize a sua (em pedaços \\
de têxtil não-tecido TNT) e depois conte aos demais \\
como ela o ajudaria a sobreviver no Espaço. Durante \\
os diálogos enquanto pintam as toalhas, um aluno \\
afirma que sua terá um dispositivo para ligar para a \\
NASA, ao que é questionado: [Sujeito 2]: Mas não \\
adiantaria ligar para a NASA, porque no livro a \\
Terra foi destruída. E ele responde: [Sujeito 1]: Mas \\
podem ter restado as estações espaciais. \\
Nesta situação, o sujeito 2 faz referência à \\
\hline Espaço \\
(10/05/2016)
\end{tabular}




\begin{tabular}{|c|c|}
\hline & $\begin{array}{l}\text { história do livro -que já havia lido-, onde a Terra foi } \\
\text { destruída, mostrando atenção aos detalhes da } \\
\text { narrativa. O sujeito } 1 \text {, no entanto, consegue } \\
\text { rapidamente pensar em uma resposta adequada, } \\
\text { lembrando das estações espaciais. Além dessas } \\
\text { percepções foi possível notar quais suas principais } \\
\text { preocupações para viajar pelo Universo onde a } \\
\text { grande maioria lembrava-se de algum dispositivo que } \\
\text { provesse alimentos e outro que oferecesse acesso à } \\
\text { redes sociais. }\end{array}$ \\
\hline $\begin{array}{l}\text { Espaço } \\
(24 / 05 / 2016)\end{array}$ & $\begin{array}{l}\text { Desenvolve-se uma atividade que consiste em } \\
\text { um circuito de etapas, tendo como base a história do } \\
\text { Lanterna Verde (JOHNS, 2013), um herói dos } \\
\text { quadrinhos. Os alunos dividem-se em grupos e inicia- } \\
\text { se uma dinâmica de mito ou verdade acerca da } \\
\text { história do personagem, onde podem conhecer mais a } \\
\text { respeito e iniciar um clima de competição. Depois } \\
\text { fala-se das características dos lanternas verde e do } \\
\text { fato deles existirem por todo o Universo. Dessa } \\
\text { maneira, na próxima etapa os grupos precisam } \\
\text { pensar em uma forma de descobrir vida em outro } \\
\text { planeta e apresentá-la para os demais. Os outros } \\
\text { grupos dizem o quanto aquela ideia foi criativa } \\
\text { dando "pontos" para a mesma. Se cada grupo possui } \\
\text { cinco pontos que deve dividir entre as outras equipes, } \\
\text { caso considere que uma equipe tenha sido } \\
\text { completamente criativa a outra nem tanto, pode dar } \\
\text { quatro pontos para aquela e apenas um para essa, } \\
\text { por exemplo. Todos os grupos criam ideias no } \\
\text { formato de narrativas, algo que não foi pedido pelos } \\
\text { monitores, mas que esteve presente em todas as } \\
\text { equipes. O grupo 1, considerado o mais criativo pelos } \\
\text { colegas tendo contabilizado a maior quantidade de } \\
\text { pontos, diz que o governo distribuiria relógios para } \\
\text { os heróis se tele transportarem para outros planetas e } \\
\text { o mesmo seria capaz de detectar vida nesses locais. }\end{array}$ \\
\hline
\end{tabular}




\begin{tabular}{l}
\hline Na última etapa há diversas bexigas espalhadas pela \\
sala, cada uma com um papel escrito dentro, mas \\
apenas uma premiada. Quanto mais pontos \\
conseguem na etapa anterior, mais bexigas podem \\
estourar e mais chances tem de ganhar. No entanto \\
nenhum dos participantes encontra a bexiga \\
premiada. Com esta atividade exercita-se o trabalho \\
em grupo, a criatividade e a conversa a respeito de \\
vida em outros planetas.
\end{tabular}

Esses são exemplos de intervenções que se configuram no modelo de atividades propostas pelo LUCIA.Ao relacionar tais atividades com a Agenda 2030 é possível observar que a primeira aborda o objetivo 10- Redução das desigualdades; a segunda de robótica (quadrinhos) fala sobre Igualdade de gênero e Indústria, inovação e infraestrutura; a atividade de Meio Ambiente com o uso do tabuleiro trata de Erradicação da pobreza, Fome zero e agricultura sustentável, Saúde e bem estar, Vida terrestre e Paz, justiça e instituições eficazes; a atividade sobre Espaço inspirada em Douglas Adams (2009) corresponde ao objetivo 3- Saúde e bem-estar e a última atividade sobre Espaço abrange o objetivo 17- Parcerias e meios de implementação. A seguir será analisada mais detalhadamente a intervenção inspirada no conto "O Fura-Greves" (ASIMOV, 1991), em que a temática da sustentabilidade tem um papel de maior destaque.

\section{LUCIA EM ELSEVERE: A SUSTENTABILIDADE ATRAVÉS DO LÚDICO}

Dentro do espaço da Escola A um dos grupos de alunos que participam das intervenções possui como tema norteador o Meio Ambiente. Os alunos estão no ensino fundamental II e possuem a faixa etária de 12 a 14 anos. O LUCIA teve a oportunidade de realizar atividades com esse grupo no primeiro semestre de 2016 e, a partir de práticas lúdicas, foi possível tratar diversas questões dentro desse assunto.

Aqui será analisada a atividade que ocorreu em março de 2016 e usou como base o conto de Isaac Asimov (1991) "O Fura-Greves", publicado originalmente em 1957. A história fala de um planetoide muito pequeno, a ponto de poder ser habitado até mesmo em seu interior por falta de espaço na superfície, onde absolutamente tudo precisa ser reutilizado. Neste lugar, 
chamado de Elsevere, a sociedade se organiza por um sistema rígido de castas, onde cada indivíduo possui uma determinada função. No entanto algumas castas possuem tratamento diferenciado das demais, como é o caso dos coletores de fezes. Seu trabalho é um dos mais importantes pois o tratamento e a reutilização das fezes gera diversos benefícios para a população. Apesar dessas pessoas terem uma boa qualidade de vida financeiramente falando, não podem se relacionar com o resto da sociedade. Isso faz com que em determinado momento os coletores se revoltem com aquela situação e parem de exercer seu trabalho, reivindicando maior participação na sociedade e o direito de se relacionar com as demais castas.

Fazendo um paralelo com a Agenda 2030 é possível estabelecer diversos pontos a serem tratados a partir da narrativa. A sociedade retratada possui diversos objetivos da Agenda 2030 como realidade, entre eles a Educação de qualidade, Água potável e saneamento, Cidades e comunidades sustentáveis e Consumo e produção responsáveis. Isto abre margem para que se discuta como seria um mundo com todas essas características e o quanto acredita-se que essas metas possam realmente ser alcançadas até a data estipulada.Por outro lado ainda há desigualdade social quando se pensa no sistema de castas, onde apesar de não ser identificado problemas financeiros nas castas consideradas inferiores, como é o caso dos coletores de fezes, estes não são permitidos a conviver com o resto da sociedade. Isto causa uma limitação e exclusão social muito grande. Observa-se então que estas pessoas passam a buscar a redução das desigualdades - objetivo 10 da Agenda - a partir de uma paralisação geral em suas atividades. Nota-se então que o objetivo 16- Paz, justiça e instituições eficazes pode estabelecer-se como um divisor de opiniões no conto. Se por um lado os coletores pedem justiça e mais direitos de convívio em sociedade, as outras castas não acreditam que seja justo precisarem ter contato com aquelas pessoas. E em meio a tudo isso a paz já foi afetada e as instituições não se mostram capazes de evitar o conflito de interesses.

O conto mostra assim uma alegoria do nosso próprio mundo, onde algumas funções são consideradas superiores a outras, recebendo mais privilégios por isso. Ainda conta com uma tentativa de separação dessas pessoas, o que pode ser observado na sociedade em que vivemos a partir da simples diferença entre bairros nobres e periferia, onde nesta encontram-se pessoas que acabam sendo mantidas distantes da sociedade. Mesmo os locais frequentados são diferentes, como as escolas, hospitais, restaurantes. A discussão trazida por Asimov é precoce, acontecendo em 1957, onde já conseguia pensar com bastante clareza sobre a preocupação com a 
sustentabilidade e notava, há décadas atrás, uma segregação social que é vista até os dias de hoje, por mais que sua fachada mude um pouco no decorrer dos anos.

A partir desta obra é proposta uma atividade que consiste em fazer uma roda de conversa com os alunos onde conta-se a história, mas sem revelar o final, a fim de que possam discutir o que acreditam que acontece no decorrer do conto e para que reflitam sobre o mesmo. Depois da discussão sobre o assunto dividem-se em grupos, onde devem produzir um desenho onde retratem o que absorveram de mais importante. Para esse desenho são disponibilizados diversos materiais, como canetas coloridas, fitas adesivas, giz de cera, lápis de cor e tinta guache. É importante notar que apesar do LUCIA ser um grupo que trabalha com a literatura, os alunos não são colocados de fato para ler textos durante as atividades. Isto se deve porque a intenção é criar atividades lúdicas onde os participantes possam ter uma experiência divertida e diferente da sala de aula. Para isso é preciso remover os padrões formais dos quais estão acostumados, de maneira que mesmo que as intervenções ocorram dentro de uma sala, ela não esteja estruturada dessa forma (optando por afastar as carteiras ou coloca-las em círculo).

Além disso, é importante lembrar que existe mais de um tipo de leitura. Para Maria Helena Martins (1997) a leitura é a percepção de expressões, independente de qual seja a linguagem em que elas estão sendo transmitidas, lembrando ainda que ler não se refere apenas a algo escrito. Dessa forma o LUCIA trabalha com diferentes tipos de leitura, focando sempre na narrativa e não no texto escrito.Durante todo o tempo em que a história estava sendo contada para os alunos, todos mantiveram-se atentos no enredo, manifestando até mesmo expressões de surpresa durante alguns momentos, como quando é contado sobre as exigências dos coletores e uma das alunas levanta as sobrancelhas em resposta. Também mostram participação efetiva no debate posterior. 


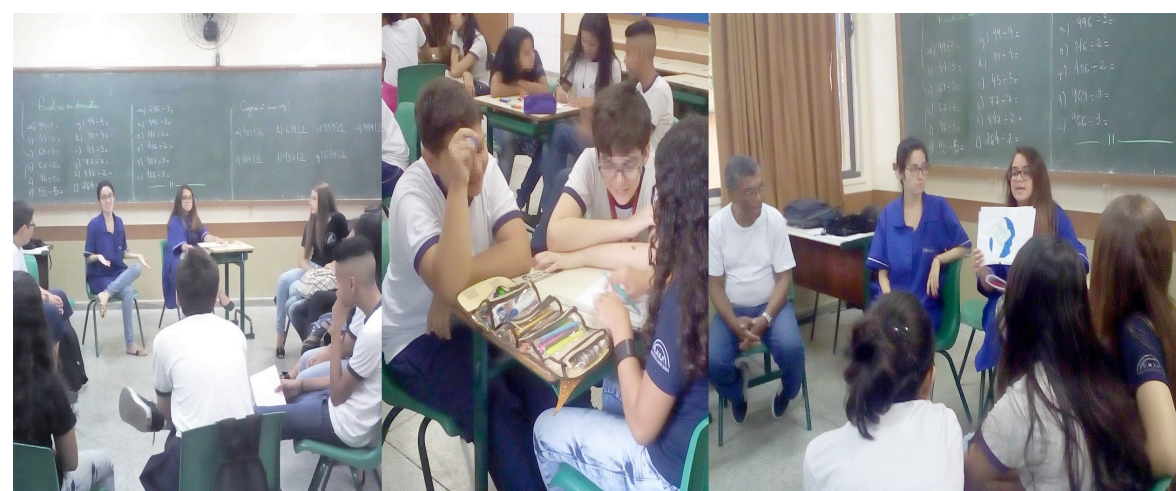

Figura 2: Monitores contando a história, alunos criando seus desenhos e explicação dos desenhos.

Para iniciar as discussões foi perguntado o que fariam caso não pudessem conviver com o resto da sociedade. Valeria a pena mesmo que possuíssem muito dinheiro? As opiniões a respeito se dividem, com parte dos alunos acreditando que seria algo viável e outros decididos que não seria possível viver nessas condições. Um dos alunos afirma que caso se encontrasse em situação semelhante, produziria energia a partir das fezes coletadas apenas para seu próprio grupo, já que as outras pessoas não gostavam deles. No entanto, no que se refere diretamente à sustentabilidade a opinião unânime é a de que seria muito complicado reutilizar tudo o que é usado pela sociedade.Encerrada a discussão, partem para a próxima etapa onde devem dividir-se em grupos e elaborar um desenho que retrate o que foi absorvido de mais importante do conto. A divisão é rápida e logo escolhem os materiais para o desenho. É importante ressaltar o papel da ludicidade presente nesta etapa. Enquanto desenham, exercitam livremente os conteúdos manuais do lazer (DUMAZEDIER, 1980). Isto permite não apenas que exercitem a criatividade, mas que se comuniquem através de um meio diferente do qual estão acostumados em sala de aula. Além disso todo o diálogo necessário entre o grupo para que seja possível a criação do desenho proporciona a discussão sobre o assunto, algo fundamental para a difusão científica.

Depois de todos terminarem seus desenhos, sentam-se em roda novamente para mostrar o que foi feito aos demais. O primeiro grupo explica que desenhou um planeta triste, com uma fábrica em greve, buscando representar o quanto aquela situação era negativa e prejudicial a todos. 
A seguir é mostrado o desenho do segundo grupo, onde foi retratado um castelo e em frente pessoas coletando fezes, o que remete diretamente a história e a vida dos coletores ali retratada.

O terceiro e o quarto grupo representam em seus desenhos situações mais ligadas à sociedade na qual vivemos. $\mathrm{O}$ terceiro grupo retrata mundos separados, onde os ricos possuem dinheiro e melhores condições de vida do que pessoas menos abastadas. Enquanto isso o último grupo faz um paralelo de como seria a casa de pessoas ricas (grandes e luxuosas) e de pessoas pobres (moradias mais simples).As duas últimas equipes deixam evidente que para eles foi difícil associar os personagens do conto de maneira diferente da realidade em que vivem. Estão acostumados a observarem profissões que por mais importantes que sejam, não possuem prestígio e seus profissionais são pouco remunerados. Já no conto, apesar da profissão ter pouco prestígio, os profissionais ganhavam bem ao exercê-la. Essa diferença entre narrativa e realidade parece ter sido um pouco complicada de associar, já que nos desenhos preferiram relatar o que observam no meio no qual estão inseridos.Essas discussões a respeito de desigualdade, seja no conto ou na vida real mostra a preocupação dos participantes com esses aspectos, o que é importante para se discutir sustentabilidade. Afinal, para que haja desenvolvimento sustentável é preciso que haja igualdade entre as pessoas, pois segundo SACHS (1993) crescimento com desigualdade alarga ainda mais as divisões entre os países.

Para finalizar, todos deveriam reunir-se novamente com seus grupos e elaborar um roteiro para um vídeo. A intenção é imaginar que criariam um canal na internet para falar de meio ambiente e sustentabilidade e que fariam um vídeo a respeito. Para tanto, deveria ser elaborado um roteiro com os temas que seriam tratados.Muitos mostram-se tímidos, porém outros afirmam que sempre sonharam em criar um canal para postar vídeos e se empolgam com a proposta. No entanto algumas dificuldades surgem durante esta etapa. A falta de tempo é uma delas, pois o como o encontro terminaria logo, precisariam criar algo rápido. Para tanto sugeriu-se que o roteiro fosse elaborado em formato de tópicos, apenas apontando os principais pontos a serem discutidos, porém não se mostraram familiarizados com a técnica.Quando o tempo se esgota, os roteiros são recolhidos. Alguns estão bem vazios, quase sem informações, mas um dos grupos consegue se destacar e entrega o roteiro com a introdução já escrita, preferindo estrutura-lo em primeira pessoa ao invés de tópicos. 
As dificuldades encontradas durante essas intervenções não devem ser encaradas negativamente, mas sim como um indicador de que algo não saiu como o esperado e que pode ser aprimorado. Nas reuniões semanais do LUCIA é revista como foi a aplicação da atividade, são identificados os pontos que não deram certo e a partir daí é possível melhorar o desempenho do grupo nos próximos encontros. A intenção é que eles sejam o mais atrativos possíveis para os participantes. É somente ponderando os erros e acertos da intervenção que se pode não apenas aprender e aprimorar as intervenções, como também perceber determinados aspectos da turma. Neste caso não mostram tanta afinidade com a escrita, mas saem-se bem nas etapas de desenho. Portanto entende-se que para aquele grupo específico é mais interessante oferecer propostas onde possam desenhar ao invés de escrever. Também é possível buscar novas abordagens, procurando conhecer os indivíduos e moldar-se a eles, de maneira que cada vez mais identifiquem-se com as atividades e sintam-se estimulados a participar.

\section{CONSIDERAÇÕES FINAIS}

Muitas pessoas possuem pouco contato ou interesse pela ciência e a difusão científica vem não como uma forma de ensinar, mas de discutir conteúdos científicos de maneiras diferentes. A partir do momento em que o assunto é apresentado de maneira atrativa fica muito mais fácil atingir um maior número de pessoas de diferentes públicos.Não é um desafio fácil elaborar uma atividade capaz de chamar a atenção, ser prazerosa e debater ciência, mas as práticas lúdicas mostram ser o braço direito nestas situações. A partir delas o indivíduo consegue se desligar por algum tempo de sua realidade e por meio de algo que muitas vezes parece simples, desenvolver-se de alguma maneira. Este mesmo papel de envolver a pessoa e transportá-la para outro lugar é desempenhado a todo momento pela literatura. Alinhando-se então essas duas ferramentas é possível criar experiências de difusão científica enriquecedoras.

Dessa forma o LUCIA se propõe a tratar dos mais diversos temas a partir de obras literárias, especial as ficções científicas. Este gênero mostra-se capaz de pensar no futuro de determinada maneira que consegue ser fantasiosa e realista ao mesmo tempo, o que estimula a imaginação e a reflexão.Ao considerar que através de uma atividade de difusão científica haverá um contato direto com os participantes e eles serão de alguma maneira afetados com aquilo, é essencial que os temas a serem tratados sejam cuidadosamente escolhidos. Assim, ao trabalhar com alunos de ensino fundamental II, entende- 
se que é imprescindível que se fale de sustentabilidade com eles, por ser algo que afeta diretamente a todos os indivíduos.Durante as atividades e posteriormente ao analisá-las observa-se que por mais que a proposta seja a mesma, cada aluno é capaz de entende-la de uma forma. Quando se leva um conto onde todo um planetoide se organiza para reaproveitar tudo o que for produzido, todos concordam que aquilo seria algo extremamente difícil de acontecer. No entanto quando se fala que alguns personagens sofriam discriminação por conta da ocupação que tinham, mas mesmo assim ganhavam muito bem, alguns associam esse acontecimento com facilidade e outros nem tanto. Bem como quando é questionado sobre a possibilidade de viver isolado do resto da sociedade, mas com uma condição financeira agradável, as opiniões dividem-se totalmente. Isso mostra como as percepções sobre um mesmo tema podem ser diferentes, e é só a partir do diálogo que se estimula o pensamento crítico e as ideias podem complementar-se.

Os objetivos 11- Cidades e comunidades responsáveis e 12- Consumo e produção responsáveis ainda não conseguem ser vistos com facilidade pelos alunos como uma realidade, como é no caso do conto. O fato de afirmarem que seria muito difícil reutilizar tudo em um planeta leva a entender que uma mudança de hábitos não parece algo tão simples para eles.

No entanto quando se fala da Redução das desigualdades e de Paz, justiça e instituições eficazes, também objetivos da Agenda 2030, todos conseguem discorrer bem sobre o assunto, apontando diferentes maneiras de conseguir alcança-los dentro da narrativa. Também conseguem, sem maiores problemas, apontar aspectos de nossa própria sociedade onde há diversas desigualdades que precisam ser superadas, como retratado nos desenhos de dois grupos, mostrando que quem possui mais dinheiro pode ter casa e condição de vida muito melhores do que as pessoas que não possuem, que acabam sendo cada vez mais desvalorizadas.

No caso da intervenção utilizando o conto "O Fura-greves" (ASIMOV, 1991) o grande problema é a falta de tempo com os alunos para a última etapa, bem como a pouca afinidade que possuem com a elaboração de roteiros. Para uma futura atividade seria interessante estruturá-la de maneira que cada uma das etapas anteriores ocupasse um pouco menos de tempo para que assim fosse possível trabalhar com mais calma durante a escrita, deixando um momento reservado para que se oriente melhor os alunos sobre como escrever ou como estruturar seus pensamentos em tópicos. 
Outra possibilidade seria reformular a atividade para que ela fosse realizada em dois dias. No primeiro seria o momento de terem o contato com a história, produzirem os desenhos e fazer uma roda de discussão sobre o tema. No segundo dia o foco seria inteiramente direcionado a produção do roteiro, podendo dispensar um tempo maior para uma explicação detalhada sobre como estruturar um roteiro, podendo contar até com alguns exemplos. Também seria possível acrescentar algumas outras características, como pedir que descrevessem qual seria o cenário do vídeo.

Vale lembrar que por mais que uma intervenção não saia exatamente como o planejado e que surjam algumas dificuldades, o papel principal daquilo é debater os assuntos. Não importa se os indivíduos não saírem de lá sabendo todos os passos para um mundo sustentável ou sendo capazes de definir o conceito de sustentabilidade, o fato de terem de alguma maneira conversado sobre aquilo já cumpre o papel da difusão científica. O mesmo vale para a leitura. Apesar do LUCIA trabalhar integralmente com livros, contos, histórias em quadrinhos, a intenção não é formar leitores, mas trabalhar aquelas narrativas. Se a partir dali surgir o interesse espontâneo por parte do aluno e o mesmo tiver contato com o livro, isso será um resultado bastante positivo. Porém, por mais que ele não se interesse em saber mais depois, o fato de ter tido o contato com aquela história já agregou conhecimento de alguma maneira.As pessoas são sempre capazes de absorver algo de uma nova experiência. Se os alunos foram capazes de refletir sobre a sustentabilidade e as relações do homem com o meio em que vive, também são capazes de tomar atitudes mais conscientes e contribuir para a transformação de uma cidade mais inteligente. Essa consciência individual é um fator importante para que se consiga atingir objetivos coletivos, como é o caso do 12- Consumo e produção responsáveis, presente na Agenda 2030, que implica em suas medidas a redução do desperdício de alimentos, atitude que precisa vir de todas as pessoas para que se obtenha sucesso.

Todas as propostas desenvolvidas pela equipe se dispõe a estimular o pensamento crítico através de abordagens lúdicas, que muitas vezes podem ser consideradas também de lazer, já que ambas geram o desenvolvimento pessoal e social.Os conteúdos culturais do lazer de Joffre Dumazedier (1980) fazem bem o papel de ligação entre o lúdico e o lazer. A exemplo disso pode-se mencionar os conteúdos manuais, que incluem pinturas - muito usadas nas atividades e que geram um momento prazeroso e de troca de conhecimento entre os participantes. São então ferramentas que adequam-se na estrutura de 
educação não formal, enquadrando-se como elemento fundamental para os resultados das atividades.

\section{REFERÊNCIAS}

ADAMS, Douglas. O guia do mochileiro das galáxias. São Paulo: Arqueiro, 2009.

ALBAGLI, Sarita. Divulgação científica: Informação científica para cidadania. Ciência da Informação, [S.1.], v. 25, n. 3, dec. 1996. ISSN 15188353. Disponível em: <http://revista.ibict.br/ciinf/article/view/639>. Acesso em: 12 ago. 2016. doi:http://dx.doi.org/10.18225/ci.inf..v25i3.639;

ALMEIDA, Maria J. P. M. de; RICON, Alan E. Divulgação científica e texto literário: uma perspectiva cultural em aulas de física. Caderno Catarinense de Ensino de Física, Florianópolis, v. 10, n. 1, p.7-13, abr. 1993;

ASIMOV, Isaac. Sonhos de Robô. Rio de Janeiro: Record, 1991;

COLLINS, Susan. Jogos Vorazes. Rio de Janeiro: Rocco Jovens Leitores, 2010;

CRUZ, Lívia D. L.Avaliação de uma proposta para politicas públicas de educação em tempo integral: Projeto A.L.I.C.E. - Arte e Lúdico na Educação em Ciências na Escola. Relatório de Iniciação Científica do Programa PIBIC. Universidade de São Paulo, Escola de Artes Ciências e Humanidades. São Paulo: 2016;

DUMAZEDIER, Joffre. Valores e conteúdos culturais do lazer. São Paulo: SESC, 1980;

JOHNS, Geoff. Lanterna Verde. Hal Jordan: Procurado - vol. 1. Panini Books, 2013;

KISHIMOTO, Tizuko M. (Org.). Jogo, brinquedo, brincadeira e educação. São Paulo: Cortez, 1999;

MARTINS, Maria Helena. O que é leitura. São Paulo: Brasiliense, 1997;

NAÇÕES UNIDAS. Transformando Nosso Mundo: A Agenda 2030 para o Desenvolvimento Sustentável. Disponível em: $<$ https://nacoesunidas.org/pos2015/agenda2030/>. Acesso em: 22 out. 2016; 
PREFEITURA. Mais Educação São Paulo. Disponível em: $<$ http://maiseducacaosaopaulo.prefeitura.sp.gov.br/>. Acesso em: 29 out. 2016;

REQUIXA, Renato. O lazer no Brasil. São Paulo: Brasiliense, 1977;

SACHS, Ignacy. Estratégias de transição para o século XXI. In: BURSZTYN, Marcel. Para pensar o desenvolvimento sustentável. São Paulo: Brasiliense, 1993. p. 29-56;

SEN, Amartya K. Desenvolvimento como liberdade. São Paulo: Companhia das Letras, 2000;

TSCHOKE, Aline; OLIVEIRA, Elaine S; PAOLONI, Lorena L; RAMOS, Pedro V. B; LUZ, Rafael G.; RECHIA, Simone; ASSIS, Talita S. ; FRIEDRICHSEN, Vanessa M. O "lugar" do lúdico na escola: composição entre simbolismo, liberdade e gratuidade. In: IV CONGRESSO SULBRASILEIRO DE CIÊNCIAS DO ESPORTE, Faxinal do Céu: 2008. P. 510-517.

Recebido em 30/10/2016

Aprovado em 01/12/2016 